\title{
A CONCEPÇÃO DE ESTADO EM OLIVEIRA VIANA (*).
}

\author{
MARIA STELLA MARTINS BRESCIANI \\ do Departamento de História da Faculdade de Filoso- \\ fia, Letras e Ciências Humanas da Universidade de
} São Paulo.

Nossa principal preocupação ao elaborar este trabalho, prendeuse a uma das dificuldades fundamentais enfrentadas pela pesquisa histórica e acreditamos, pelos pesquisadores da área de Ciências Humanas em geral. Como realizar um estudo crítico sobre um autor, um grupo social, um grupo político, sem deixar-nos levar para o campo das "influências sofridas" ou simplesmente enunciarmos de forma ordenada as principais preposições do autor? Em suma: como interligar o texto ao contexto, ou seja a documentação utilizada e a realidade vivida pelo objeto do estudo? Nossa documentação visa contribuir para encaminhar esse problema.

O objeto de estudo escolhido foi Oliveira Viana, estudioso da sociedade em geral e da brasileira em particular, autor de numerosos trabalhos cujo núcleo de preocupação reside na política brasileira. Sua atividade como pesquisador cobre três décadas, aproximadamente (1920-1950) e, numa primeira abordagem, apesar do núcleo comum - a política brasileira - a forma de expressão e a qualidade dos termos utilizados pareceram variar consideravelmente. Entre algumas dessas variáveis a que nos pareceu bastante expressiva foi o progressivo aumento do número de citações de autores, tanto no que se refere a métodos de análise sociológica como na coleta de informações. Poderíamos falar, no caso de Oliveira Viana, num gradual abandono de "ensaismo" para um critério de trabalho "mais científico"?

Nosso desconhecimento de uma história da sociologia do final do século passado e da primeira metade do atual (a maioria das obras sitadas prende-se a esse período) nos dificultou tentar captar as "influências" e as "adesões" sofridas pelo autor que estudamos. Dessa

(*). - Comunicação apresentada na 2a. sessão de Estudos no dia 6 de julho de 1972 (Nota da Redação). 
maneira a dificuldade nos forçou a um estudo dos textos do autor, num esforço de conhecimento "de dentro para fora".

Tomamos como base para o estudo da concepção do Estado em Oliveira Viana dois de seus trabalhos, Problemas de Política Objetiva e Instituições Políticas Brasileiras, que reputamos importantes para apreender o autor. Definimos esta importância pelos momentos históricos a que estão ligados: o primeiro compõe-se de uma coleção de ensaios publicados no período imediatamente anterior a 1930, e cuja segunda edição de 1947 saiu sem modificações, pois sıbstancialmente não há nele alteração de uma idéia sequer (p. 24), e o segundo, editado em 1947, estudo que pela forma de proposição de trabalho do autnr e por seus preceitos metodológicos, constitui num reaproveitamento de seus estudos anteriores, elaborado com o fim de propor uma organização e atuação do Estado no Brasil. Sua preocupação sistemática "numa atitude de rigorosa imparcialidade e objetividade" sempre tendo em vista a aplicação prática, forneceu-nos o elemento de base para o trabalho.

O exame do material foi realizado em três etapas: primeiramente tentamos captar nos textos, objetivo, método e técnica e confrontá-los com objetivo, método e técnica propostos. Numa segunda etapa procuramos encontrar a estrutura lógica que ele desenvolve para expor o resultado de suas pesquisas, tentando numa terceira etapa apreender o significado dessas proposições do autor para a época. E' importante dizer que este trabalho representa uma procura de método e técnicas de análise, sendo porém necessário explicitar o muito de tentativa e erro existente. Na verdade nosso objetivo foi o de atenuar uma análise impressionista. Consistiu preocupação paralela a da apreensão da lógica do pensamento de Oliveira Viana, o estudo qualitativo de seu vocabulário, de certas palavras reveladas importantes pela etapa $n .^{\circ}$ 2 da análice, sua significação e o contexto em que aparecem.

Para o texto de Problemas de Política Objetiva, sua exposição compõe-se de quatro unidades fundamentais ao desenvolvimento lógico de seu raciocínio:

- realidade brasileira

- proposições para a realidade brasileira

- realidade internacional

- ideais "filosóficos" reais (atuais).

Consideramos a utilização des cas unidades somente na medida em que eram indispensáveis para a ligação entre um item da exposição $\mathrm{e}$ o imediatamente seguinte. Não tentamos quantificar a intensidade de ocorrência de cada uma, apesar de acharmos que seria um dado im- 
portante, e apesar ainda de, no caso deste texto em especial, deixar de lado a maioria das recorrências que o autor faz às "realidades" de países europeus específicos e dos Estados Unidos. Achamos interessante fixar que o autor recorre, para exemplificar formas adequadas de atuação, tanto aos Estados Unidos quanto a vários países europeus, tais como, Alemanha, Inglaterra, França e Rússia, independendo sua apreciação das formas de sistemas políticos existentes nesses países. Assim, para exemplificar a necessidade de agrupar a povo em organizações de classes (sindicatos profissionais) ele toma a experiência alemã, demonstra a viabilidade de sucesso da coletivização da propriedade e produção agrária voltando-se para o caso soviético, afirma a necessidade de educação e tradição política buscando os elementos da organização político-social da Inglaterra. E' interessante fixar que somente uma vez apanha procedimentos ineficientes dessas "grandes democracias" e neste caso não busca particularizar a general:zação que faz.

\section{A utilização e o conteúdo dessas unidades.}

Partindo do objetivo dado de seu estudo, ou seja a estruturação social e política do país, e percorrendo o caminho por ele proposto, o da "investigação das realidades" dentro de uma "atitude mental" "idêntica ao dos etnólogos ao investigarem as sociedades primtivas", o que pressupõe, pela posição do autor, um distanciamento e uma neutralidade de investigador frente à sociedade analisada.

Inicia sua exposição a partir da constatação de uma realidade brasileira, a necessidade de revisar a Constituição de 1891 , prossegue seu raciocínio utilizando sempre mais três elementos, proposições para esta realidade, proposições que buscam "fazer evoluir" a realidade existente de ideais filosóficos atuais encontráveis nas respostas dadas por países reconhecidamente mais avançados a situações que enfrentaram - realidades internacionais. Em síntese, ele advoga uma posição realista, uma necessária maleabilidade dos ideais filosóficos, re não em termos de objetivos, pelo menos no que respeita aos meios para atingi-los. Essa posição de pragmatismo fica bastante visível tanto pela frequencia com que recorre às realidades, tanto pela forma como utiliza os ideais filosóficos atuais. E' sempre uma colocação polêmica e atual. Isolando-os do texto, ele coloca o falso do debate liberdade e democracia contra a civilização e nacionalidade, explicando que civilização e nacionalidade são caminhos para os dois primeiros, ou seja a integração nacional constitui uma força civilizadora o que torna os povos fortes e dominadores, povos que ele opõe aos fracos e dominados. Outra colocação sua e quanto à necessidade de anti-personalismo 
na política, devendo as plataformas serem de partido e não do candidato, ou seja numa verdadeira democracia é indispensável a colaboração não de indivíduos mas de grupos-partidos de classes e não princípios gerais de doutrina política. Retoma mais adiante a impossibilidade de atuação "atomística" e mostra que nos governos modernos a pressão democrática só pode ser exercida por sólidas organizações de classes ou de partidos, afirmando ainda que a força desses grupos provém da solidariedade e não da riqueza. Sua última colocação em termos gerais é a correta atitude do cientista social moderno - sem preconceitos de escola ou de filosofia, - atitude essa cuja eficiência mostrou a inexistência de raças inferiores, deslocando o problema para a esfera da adaptação do homem ao meia em que vive.

Fica bastante visível o pragmatismo de seus pressupostos teóricos se pensarmos que recorre aos "conceitos" de Democracia, Liberdade, Civilização (progresso) e Liberalismo (na nota introdutória) somente quando pretende demonstrar que os caminhos que propõe levam a esses objetivos "filosófcios" gerais.

Esta forma complementar de utilização de conceitos ideais contrasta fortemente com a persistência de elementos da realidade, tanio brasileira como internacional, e a utilização destes dois elementos para construir as proposições para a realidade brasileira. Sua preocupação de atuação prende-se exclusivamente ao Brasil, e a utilização de exemplos externos vem confirmar ou negar viabilidade de atuação interna. Não encontramos proposições ou sugestões para os outros países, e que de certa forma acentua o sentido prático de seu trabalho: todo ele é voltado para a crença na possibilidade de ação.

A unidade mais extensamente utilizada é a de análise da realidade brasileira. Sumariando suas colocações. Ele vê na aceitação a priori de formas superiores de governo uma attude preconceituosa e afastada da realidade, que possibilitou a instituição de uma forma ideal de governo - república federalista - considerada perfeita, que torna as lutas entre posição e oposição vazias de conteúdo: a oposição sempre acha que as coisas andariam melhor se eles estivessem no poder. Portanto essa posição deforma a realidade na medida em que centra o debate num falso problema ou seja, na existência de homens que podem manejar melhor a máquina administrativa, o que leva a uma visão me siânica de líder político. Ainda nessa aceitação a priori de formas superiores de governo, a polêmica instala-se no nível da escolha entre formas de governo, não levando em consideração a capacidade e a cultura política do povo. Um dos pressupostos pensados é o da existência de sentimento de unidade nacional, quando o que existe são "estados de consciência puramente intelectuais sem condições de ob- 
jetividade pragmática nas formas cotidianas de conduta". Essa realidade coitdiana é a ausência de tradição cívica, e a incultura democrática, são os costumes de faccionismo e politicagem que infiltram-se através do Município pelo Estado e pela União até atingir o Poder Executivo dessa União.

Oliveira Viana afirma que constatou-se a necessidade de revisar a Constituição de 1891, e que essa atitude é muito nova pois "há vinte anos atrás ela era considerada intocável". Entre os itens a serem repensados está a prática do sufrágio universal, que vem demonstrando nesses quarenta anos de República a não concordância entre estrutura política e a realidade social, agindo consequentemente como "agente de dissolução íntima da nacionalidade". Esta é outra das deformações de visão a que a perspectiva anteriormente explicitada leva nossos estadirtas: a preocupação com a liberdade no nível político quando ela não existe ainda no nível individual, civil. A acepção idealista da Liberdade faz com que esses estadistas aceitem com repulsa a presença de conceito pragmático da liberdade política, como no caso da intervenção e instalação dos americanos no Haiti. "Presos a um ideal teórico de liberdade esquecem-se qua o verdadeiro problema está na oposição liberdade-nacionalidade, numa tendência centrípeta para a organização político-administrativa que já penetrou na subconsciência coletiva".

Ainda essa aceitação de liberdade ligada à descentralização política, esquece que a gratidão e a amizade constituem a base dos partidos político. Assim só os intelectualistas acreditam na eficiência das campanhas democráticas, que pressupunham "a força lógica do raciocínio e da dialética como agentes determinantes da conduta das multidões". Na realidade a população, principalmente a do interior está distribuída em grupos partidários fechados, o sistema de clã, o que em outras palavras significa que apóiam homens e não idéias. Essas campanhas de pouca utilidade imediata são úteis a longo prazo, levarão ao conhecimento das necessidades e interesses das regiões percorridas Teremos então uma visão mais correta da realidade, atitude bastante diferente da dos legisladores de 1891, bacharéis que legislavam sobre assuntos que desconheciam na prática ("sobre agricultura sem ouvir os agricultores, sobre industria sem ouvir os industriais"). A elaboração das leis sem apelo à competência técnica consistia obra legislativa da pequena elite no poder, a classe política .

Oliveira Viana afirma que a Revolução de 1930 trouxe "o espirito de colaboração técnica dos órgãos repre entativos das classes produtoras". A importância dessa colaboração pode ser sentida na eli-minação de dois erros básicos da atuação da classe política - erro de 
técnica com a elaboração de leis imperfeitas e erro de psicologia coletiva com a impraticabilidade de leis sem a adesão moral do povo a elas.

Ainda mostrando a penetração de certas atitudes inovadoras o autor analisa os três Conselhos (Educação - 1911, Trabalho - 1923, Indústria e Comércio - (1923) compostos de competências e especialistas da alta administração, dos centros de pesquisa especializada e das as:ociações de classe e salienta a atuação ineficiente desses órgãos modernos, que sofrem os preconceitos da elite política. Acentua esse "daltonismo" da visão da elite dirigente, com o desinteresse delas frente aos reais problemas nacionais, tais como, o da seca do norde te e suas consequências, o migrantismo (consequência positiva) e o banditismo (consequência negativa); e com a aceitação do satrapismo e do coronelismo, considerados símbolos nacionais do self-government. Com sua visão assim deformada, nossas elites políticas têm aplicado "literalmnete as conclusões, fórmulas e soluções de sociólogos, legisladores e estadistas europeus" ao Brasil.

Podemos esquematicamente dizer que Oliveira Viana vê dois níveis de realidade brasileira: o da visão e atuação das elites políticas e o da realidade social. Níveis sem aproximação. No primeiro caso, elite condicionada a pensar teoricamente seu nível de atuação, a importar fórmulas externas para condições brasileiras, a desconsiderar a real condição da sociedade que governa. Portanto defazamento entre instituições e sociedade.

A unidade proposições para a realidade brasileira foi bem menos explorada e sua importância é maior na parte inicial do texto. Sumariando suas colocações: necessidade de revisão dos nossos ideais políticos, o que formulará as bases da Constituição "nas virtudes comuns do povo e não na sublimidade do liberalismo e da democracia". Devemos reconhecer nossa condição de povo em formação: portanto uma integração nacional que pressuponha unidade política, sendo que a liberdade política é possível só depois de organizada a liberdade civil c os poderes judiciários e executivo.

Necessidade de pensar nossa realidade a partir da experiência de quarenta anos de República, aproveitando as experiências alheias, tais como os conselhos técnicos. Reconhecimento do idealismo da Constituição frente à realidade do difuso da idéia de nacionalidade, só possível com uma consciência nacional que ainda deve ser formada. Constatação de que o problema central não é o da persistência do sufrágio universal - liberdade política - mas sim o da liberdade civel, dissoiução do clã. Também a eleição do legislaitvo e a organização do ju- 
diciário são menos importantes do que a organização do órgão supremo moderador destes poderes.

Oliveira Viana mostra também a necessidade de uma atitude de cientista, não vinculada filosoficamente, para permitir percepcionar os prob'emas reais. Foi esta atitude que permitiu a Alberto Torres perceber a necessidade de um sentido nacionalista, uma preocupação americana, uma reação contra a excessiva europeização da vida e da cultura. Esta atitude também ajudou-o o perceber o falso da aceitação da inferioridade de raças, sendo o verdadeiro problema o ecológico, o da adaptação do homem ao meio.

Tentando apresentar esquematicamente suas proposições, notamos que 'ua principal preocupação reside na adequação da a+uação política à realidade, ou seja, no reconhecimento de sermos um povo em formação. Portanto a formação da unidade política é o ob etivo de suas proposições. E' interessante notar nessas proposições ausências de obietivos gerais, o que encontramos são proposições práticas consideradas pelo autor como vinculadas à realidade. A justificativa dessas proposições é feita recorrendo-se a realidades internaciona's.

A unidade realidades internacionais é bastante utilizada e como já dissemos não foi exaustivamente pesquisada, fazendo parte do esçuema de raciocínio quando necessária para a explicação deste.

Sumariando suas colocações, Oliveira Viana fala da posição atual frente ao princípio da self-determination: o reconhecimento, principalmente após a Guerra (este trecho não deveria fazer parte da 1.a edição, mas reforça sua posição em particular quanto ao debate sobre a intervenção americana no Haiti) da necessidade de um controle internacional das soberanias nacionais em favor da ordem e da segurança da grande comunidade internacional.

No nível da organização interna das nações, ele coloca a impossibilidade de sentimento de unidade social numa sociedade sem "ossatura de classes, sem classe superior para as umir a direção política". Mostra a atualidade do antipersonalismo na política, com plataformas do partido e não do candidato, e para a existência dessa realidade a necessidade da participação das classes econômicas como grupos de pressão, características das verdadeiras democracias.

Acentua a utilidade dos conselhos técnicos para os governos modernos, mesmo sendo sua ação de caráter meramente profissional, como fonte de informação dos interesses coletivos. Foi essa a realidade revelada pela Guerra: "a incapacidade das elites propriamente políticas para governar e administrar". Oliveira Viana considera, tendo em 
vista essas "verdadeiras democracias", que o Parlamento é um luxo caro que elas não podem deixar de cultivar já que muitos dos cidadãos ainda acreditam nele, mas enfatiza a sua importância decrescente nos sistemas políticos contemporâneos. Assim, o centro de gravidade da vida política de-locou-se do parlamento para o Gabinete, isto é, para um primeiro ministro e seus colaboradores, pessoais e técnicos. Sua última colocação lembra que as "democracias de verdade" consideram a importância da psicologia das massas e tomam conhecimento dela através de sondagens, inquéritos e da colaboração dos Conselhos Econômicos.

Esquematicamente: Oliveira Viana reconhece as mutações do liberalismo internacional, o envelhecimento do princípio da self-determination, das elites políticas, e a tendência centralizadora do poder estatal que chega até o dirigismo. Nota-se a ausência completa de preocupação do tipo de relacionamento entre essas unidades naconiais, os paíres são implicitamente considerados unidades autônomas, cujas soberanias serão controladas "em favor da ordem e segurança da grande comunidade internacional". Sua apreensão da globalidade dessas relações internacionais aparece vaga impossibilidade de existência de unidades nacionais (ou melhor de desunidades nacionais) desorganizadas, sendo a opção organizar-se ou ser dominado aceita como "natural".

Isolamos do texto algumas constantes de seu vocabulário que consideramos significativas.

revisão

realidade

princípios

estrutura do governo

formas de governo

partidos políticos, facções

cultura política, incultura democrática, ausência de tradições cívicas, atomi mo

nacionalidade, unidade política, sentimento de unidade nacional, integração nacional

democracias de verdade

massa, povo, classes baixas, plebe

classes sociais, classes produtoras, classes baixas, classe dirigente, grupos organizados, ossatura social, sindicatos profissionais, classes econômicas, classe política, consciência coletiva, consciência de classe

elite do poder, elite de bacharéis, elite política, legi-ladores, classe política

liberdade política e liberdade civil. 
A maioria dessas unidades são definidas explícita ou implicitamente pelo autor. Assim, quando fala em revisão vemos claramente que sente um processo de mutação que emerge para ele na forma do relacionamento entre sociedade e Estado, e na composição desse E:tado e dessa sociedade. A realidade constitui a percepção da sociedade com uma atitude científica ressa atitude não fica bem definida - "como a dos etnólogos frente às sociedades primitivas, ou quando se refere a Alberto Torres, agnó tico e evolucionista mas sem preocupação de escola"). Os princípios constituem os preceitos básicos do liberalismo, mas não utilizados também com conotação mais prática (princípio da unidade nacional) sua utilização é mais genérica portanto, normalmente se refere a pontos básicos. Estrutura de governo aparece ligada aos três poderes: Evecutivo, Legislativo e Judidiário; e aos três níveis: município, estado, união; mas alarga-se na consideração das formas de participação junto a estas esfera- do governo. Formas de governos é utilizado para mostrar a ineficiência do debate entre presidencialismo e parlamentarismo, ficando implícita a consideracão sobre as inúmeras possibilidades que deverão adequarse à realidade social. Partidos políticos deixa bastante clara sua percepção da realidade brasileira - existência de facções de clãs e o que pretende como partidos de classes. Cultura nolítica constitui para o autor um pressuposto necessário para a existência de uma democracia com participação coletiva, está ligada ao caso brasileiro à incultura democrática, ausência de tradições cívicas, atomismo. Nacionalidade é a base de seu obietivo - organização da democracia no Brasil - definida pela unidade política, sentimento de unidade nacional, integração nacional. Democracias de verdade constitui o ponto de referência para a qualificação do obietivo - a democracia ideal não estritamente teórico mas baseado nas práticas democráticas existentes. Massa, povo, unidade de análise utilizada indistintamente para as democracias de verdade (menor incidência) e para nosso país, unidade democrática em formação, referido às classes baixas, plebe . Classes sociais é bastante utilizado por Oliveira Viana com dupla finalidade que muitas vezes se confundem - estrutura social, estrutura cconômica. Como estrutura social ele reconhece na exirttência delas a ossatura social, sem a qual teríamos a desorganização, porque a ausência de uma classe dirigente. Ainda no nivel social que confunde-se com o político temos classes baixas, classes dirigentes, classes políticas, consciência coletiva esta última ligada à consciência nacional, consciência de um interesse nacional. No nível econômico temos classes produtoras, grupos organizados, sindicatos profissionais, classes econômicas, consciência de classe ligada essencialmente a interesses e aspirações de grupos profissionais. Elite aparece sempre qua'ificada 
como o grupo dominante, portanto conotação política, elite no poder, elite de bacharéis, elite política, legisladores, classe política. Aparece contraposta ao resto da sociedade, os dirigentes, mas sua conotação no caso brasileiro é bastante negativa, (elite dos melhores ainda tendo de ser formada) grupo ligado a ideais universais e não à realidade de nosso país. Liberdade aparece sempre qualificada como política ou civil e individual. Sua utilização é bastante prática, ou seja ele analisa os limites da proposição teórica na prática.

A análise dessas unidades de seu discurso confirmam o sentido pragmático de seu trabalho, o conceito é construido a partir da constatação de uma realidade, mostram sua vinculação às formas atuais de utilizaçã̃o dos conceitos do liberalismo. Esta vinculação aparece sempre justificada, isto é, Oliveira Viana, que se classifica como um liberal, sen ${ }^{+}$as alterações sofridas em conceitos básicos do liberalismo clássico dentro do processo de transformação histórica. Politicamente o autor classifica-se como liberal mas define-se metodologicamente como sem vinculações ideológicas, preso a uma postura científica.

3. - Para o texto de Instituições Políticas Brasileiras sua exposição também compõe-se de quatro unidades fundamentais:

- realidades internacionais

- realidade brasileira

- proposições para a realidade brasileira

— ideais filosóficos atuais.

A análise deste texto obedece aos mesmos critérios do anterior. Partimos do objetivo dado, a organização da democracia no Brasil; do método, atitude de rigorosa imparcialidade e objetividade no exame da realidade è da técnica, do particular para o geral (estudo dos grupos regionais - seu comportamento e sua consciência cívica). A constatação mais evidente, numa primeira aproximação para isolar a estrutura lógica de sua argumentação e os elementos componentes desta estrutura, constitui a densidade do seu discurso, ou seia a definição precisa dos elementos utilizados, e a intensidade de uso derses elementos encontrados em forma muito mais dispersa no trabalho anterior. O esforço de síntese é algo nítido em todo o texto.

Oliveira Viana recorreu muito pouco a unidade ideais filosóficos ituais, utilizando-a só quando úteis para definir melhor seu ob:etivo. Ao mostrar como sua postura de analista social só é conseguida através de um método imparcial e objetivo composto de técnicas matemáticas que possibilitam esta posição. Novamente fica clara a formulação implícita de desvinculação ideológica através de um proce- 
dimento científico a constatação da realidade empírica. Fica totalmente aceito como a priori indiscutível a necessidade de medir a consciência cívica, isto é, o grau de' vocação política frente às instituições vigentes. Acentuamos essa colocação por pensarmos que faz parte da visão global que o autor tem de democracia e por ser esta o objetivo de suas preposições.

Recorre novamente à unidade ideal ao conceituar democracia como uma organização social e política, cuja característica principal é a participação coletiva, isto é, não a atividade individualizada dos seus cidadãos mas na atividade deles como membros de uma corporação, como parcelas de um agrupamento, unidos pela consciência de um interesse comum de classe. Somente quando da existência de consciência coletiva teremos cidadãos capazes de utilizar o voto, "um dos elementos mais eficazes da democracia". Outra unidade utilizada visa aproximar uma percepção de processo social visualizado por Oliveira Viana como mudanças endógenas e mudanças exógenas. As primeiras "dependem de mil fatores de toda ordem" como as enormes mudanças sofridas "pela estrutura e mentalidade das sociedades modernas sob a ação exclusiva das invenções e progressos da tecnologia". Constituem "obras do tempo, nascem de lentas e imperceptíveis desintegrações de complexos culturológicos e de alterações morfológicas, paulatinamente processados na estrutura do grupo. As transformações exógenas são as preparadas pelo Estado ou forçadas por ele dentro de um plano de reformas organizado, por um partido, por uma elite ou por um gênio político, utilizando a poderosa máquina executiva e coercitiva do Estado. Lembra que mesmo dispondo destes meios"... um grande espaço de tempo terá que decorrer até que a cultura do grupo dominante imponha seus caracteres, eliminando os da cultura do grupo dominado, através do mecanismo seletivo com que se processa a sua integração".

Fixados esses pontos básicos em alguns momentos da sua exposição Oliveira Viana não mais recorre a esses elementos utilizando de forma quase sempre alternada realidade brasileira e proposições para a realidade brasileira. Confirma-se o sentido prático que imprime ao seu trabalho tanto no nível das generalizações quanto no nível e in1ensidade das proposições para modificar a situação atual brasileira.

A utilização das unidades realidades internacionais. Reconhece a existência de dois tipos de democracias modernas, as de opinião organizada e as sem opinião organizada. Em cada caso devemos reconhecer a especificidade do povo, sua "substrutura de modos de ser", que determina "uma estrutura irreversível verificável principalmente 
no campo das instituições políticas" que para funcionarem devem obedecer às condições de vivência do grupo.

$\mathrm{Na}$ década de 20 e 30 as ciências sociais desprenderam-se da Filosofia social e constituiram-se definitivamente dentro das regras de uma metodologia rigorosamente objetiva - principalmente os mestres americanos - ou seja "inquéritos em que não intervenham preronceitos ideológicos". O autor utiliza outros elementos da realidade internacional sempre de forma complementar para exemplificar processos bem ou mal sucedidos. Em parte este seu procedimento explica-se pelo grande esforço de sistematização adotado no desenvolver do trabalho, ele dedica a primeira metade do texto ao exame da evolução das sociedades numa tentativa de sociologia da história de entidades nacionais. A segunda parte do trabalho, a utilizada por nós, contra sua preocupação nos problemas brasileiros, e reconhece que os métodos sociológicos científicos reconhecem a realidade - democracia de opinião organizada e democracias sem opinião organizada. Portanto no processo democracia sem opinião organizada para democracia com opinião organizada a intervenção pode-se dar em dois momentos: constatação e encaminhamento das mudanças.

A unidade realidade brasileira. Constatada a existência de uma democracia sem opinião organizada, pois os edificadores de regimes no Brasil, "na obsessão de sumariarem o que de mais alto existe nos ideais da civilização ocidental nunca buscaram-se nas condições reais da nosssa sociedade. $O$ autor ćlassifica esta atitude como expatriação cultural e individualismo da parte dos chefes políticos locais que encontram nas nossas instituições a possibilidade de prolongamento de atuarem em função de seus próprios interesses. Ele volta a falar da falsidade da presúnção de uma unidade política constituida e acentua que ersa unidade só existe no espirito das elites cultas e não na consciência do povo-massa "um conglomerado de nódulos culturais" (portanto impossibilidade de consciência coletiva, "que caminham para uma unificação geral à medida que a circulação material e espiritual se intensifica". Reconhece três grupos locais: centro-sul (o mais importante, o construtor da nacionalidade e da independência); o extremo sul (também possuidor de sentimento de nacionalidade adquirido com as prolongadas guerras de fronteiras); grupo nordestino (com ausência de capacidade de autonomia). Temos assim o falso do pressuposto de uma unidade constituida. Para Oliveira Viana essa ausência de integração nacional, portanto de consciência nacional é $o$ que determina o "fracasso das inovações liberais realizadas junto ao povo-massa, e toma como exemplo a tentativa do governo de deixar rue a população do campo criasse expontâneamente solidariedades fa- 
cultando-lhes a sindicalização. A não obrigatoriedade determinou a inoperância da medida. Ele continua a mostrar a ineficácia das técnicas liberais na estruturação da democracia no nível da organização política - federalismo - que resultou nas oligarquias; ou seja, o clã eleitoral "uma expressão legítima do nosso Direito Público Costumeiro" e ainda na admissão da uniformidade da população na instituição do sufrágio universal.

Assim, nunca preocupa "ao idealismo democrático o problema da formação do eleitor" tanto o homem do campo como o da cidade sem oportunidade de organizarem-se "cm instituiçõesi sociais que educassem na prática do direito de voto, na escolha de seus administradores". Somente com a atual organização sindical das classes é que "as nossas populações urbaras estão começando a praticar uma autêntica escola de democracia direta - o sindicato de classes".

Reconhecimento de uma democracia sem opinião organizada e demonstração da ineficiência de técnicas liberais, tentadas.

Proposições para a realidade brasileira. Evoluirmos de uma democracia sem opinião organizada para uma democracia de opinião organizada constitui o problema básico da nossa organização política e social. Reconhecida a ausência de homogeneidade da população chegamos ao falso de um pressuposto de uma unidade constituida. E' necessário formar o sentimento dessa unidade, o que constituirá a uma consciência coletiva de interesse. Uma das barreiras a formação dessa unidade é o federalismo e consequência a força das oligarquias. Para Oliveira Viana o principal não é destruir as oligarquias, mas transformá-las de oligarquias broncas em oligarquias esclarecidas, o que representari a "expansão da única forma de democracia possível no Brasil" ou seja "o governo dos melhores". O autor encaminha suas proposições mostrando que outro entrave a nossa organização política é a importância dada ao Parlamento "ao qual insistimos em acorrentar o Executivo desde 1824". Portanto existe a necessidade de diminuir a força do Parlamento. Outra medida importante é libertar o governo central dos partidos locais, não confundindo descentralização administrativa (necessária para o território extenso do Brasil) e descentralização política. Nossa solução consiste na "desconcentração", solução intermediária em que a unidade política do Poder Central - condição essencial da unidade nacional" se mantém.

Necessitamos revicar também nosso sistema de eleições, a pluralidade de nossa estrutura cultural e a diversidade de estrutura ecológica pede também uma pluralidade de sistemas eleitorais. Nosso 
problema é o da formação do eleitor, transformar o homem atomizado em molécula de qualquer associação de interesses extra-pessoais (econômico, beneficiente, artístico, mesmo esportivo). Ainda é nosso problema a formação dos partidos, não mais presos ao clã eleitoral de interesse individual mas solidarizado em torno de um objetivo de partido.

Reconhecidos os problemas a serem superados e expostos os objetivos dessa transformação, Oliveira Viana discute sua viabilidade. Demonstrada a ineficácia do idealismo da Constituição de 1891 que pretendia formar a democracia através de técnicas liberais, ou seja demonstrado o não expontaneismo da formação da solidariedade de grupo e da consciência cóletiva do povo, resta-nos estudarmos as várias técnicas autoritárias. Elas constituem as transformações exógenas, transformações operadas por uma ação consciente e deliberada do Estado. Esta ação estatal deve oberecer a um plano de reformas, organizado por um partido, por uma elite ou por um gênio político. O E tado constitui o meio para processar essas modificações, atuando na "aceleração do processo desentegrativo", processo longo de imposição "da cultura do grupo dominante" e eliminação dos caracteres da cultura do grupo dominado.

Oliveira Viana propôe ainda a reforma do Judiciário obietivando a "liberdade civil" e "individual do povo-massa", livrando-o do sistema de feudo e de clã், da justiça estadual como o juiz nosso e da polícia política, o delegado nosso.

Esquematizando: o obietivo dado de suas proposições é a formação de uma democracia de opinião organizada o que deverá ser processado em níveis, no da organização da estrutura de poder (município, estado, União), no da organização das atribuições dos diversos poderes (Executivo, Legislativo e Judiciário) e no da formação da consciência nacional do povo-massa (agrupado em grupos de interesses coletivos) e na formação de uma elite dirigente capaz (voltada para a realidade brasileira e não para o idealismo das proposições teóricas ou para os modelos externos de formas de organização políticosocial).

A seleção das constantes mais significativas de seu discurso apresentam para este texto uma dificuldade maior. Percebe-se a infiltração de extensa terminologia "científica", tal como, opinião organizada, substrutura e estrutura, estudo do comportamento e de consciência cívica, mudanças endógenas e exógenas, técnicas liberais e autoritárias de governo. A utilização destes termos aparece clara e definida, o que dá maior sistematização e precisão à sua análise. Assim 
opinião organizada subentende uma unidade nacional com uma população com consciência coletiva, que por sua vez pressupõe essa população agrupada em classes de interesses comuns. A palavra subestrutura sintetiza uma das formas de realidade, a estrutura inconsciente que governa o comportamento cotidiano da sociedade. O termo estrutura aparece não só como estrutura de governo mas também como estrutura da sociedade sendo as insittuições politicas um dos seus componentes. O conteúdo deste termo usado isoladamente não aparece perfeitamente definido. A percepção da Consciência cívica surge acompanhada do estudo de comportamento como técnica de apreensão da realidade dos grupos regionais e possuem eficiência pois tomam como ponto de referência o relacionamento com as instituições vigentes. Mudanças endógena se exógenas aparecem como importante aquisição de técnica de análise, institui os limites de possibilidade de atuação humana junto ao "processos normal de evolução". Enfim as iécnicas de atuação possíveis são divididas em liberais e autoritárias, cabendo às liberais atuarem no nível da legislação e às autoritárias uma atuação em dois níveis, no da legislação e no da ação coercitiva do aparelho estatal. Os outros termos coincidem em linhas gerais com os do texto anterior.

4. - Faremos uma aproximação ampla na tentativa de apreender alterações significativas no conteúdo e encadeamento lógico do discurso de Oliveira Viana em duas ocasiões distintas, separadas por 37 anos — 1930 a 1947 — período que assistiu a modificações tanto internas (na forma de governo, golpes de força e reestruturação de valores sociais) como na esfera internacional. A montagem de seu raciocínio oferece-nos essa possibilidade:

Para o caso do primeiro texto, a partir de um objetivo dado organização político-social do Brasil - temos a constatação da realidade da sociedade e da realidade das instituições montada por uma elite político-cultural. Emerge do estudo dessas duas realidades a siunação de não correspondência da última à primeira. No nível ideológico temos sua percepção do envelhecimento dos "princípios libetais" de self-determination, tanto no nível do indivíduo como no nível das nações, o que o leva a ver uma unidade nacional e uma grande comunidade internacional, devendo os dois níveis funcionarem harmoniozamente. Implicitamente Oliveira Viana aceita a possibilidade de um interesse nacional que integra toda a população de um país e de um interess mundial que integra as nações.

Esquematicamente suas proposições podem ser pensadas da seguinte maneira: 
análise da realidade social

análise da realidade política

instituições jurídico-políticas

organização social e política incultura democrática desorganização política

instituições presas ao liberalismo teórico, defazadas da realidade social

adequadas à realidade no sentido de organizá-la

indivíduo dissolvido no grupo

unidade nacional

No caso de segundo texto, a construção de seu raciocínio partc do objetivo - organização da democracia no Brasil, o que pressupõe a organização social e política agora definida explicitamente na forma democrática. No primeiro texto a organização social e política tendo em vista a integração nacional é considerada como camiiho para a democracia e o liberalismo, mas sua colocação aparece bem menos clara, poderíamos mesmo dizer que sua preocupação central é a unidade nacional e a forma de governo dessa unidade parece ainda indefinida.

$\mathrm{O}$ autor parte da análise da realidade nacional reconhecendo a inexistência e de condições de possibilidade de existência da organização democrática no Brasil e busca possibilidades de chegar-se até ela. Podemos dizer que universo teórico constitui-se de um a priori básico, ideal a ser atingido - centrado no conceito de democracia como participação política - que ele constata não ser a prática do "poyo brasileiro" por não ser concorde com a realidade social. Assim, sua análise cumpre dupla finalidade: constata a inadequação das técnicas liberais à realidade social brasileira e equaciona essa realidade. Esse mecanismo de alternar as duas realidades demonstra eficiência na ênfase que consegue dar a defazagem existente entre as duas. A partir desse estudo ele busca formas políticas, que adequadas à realidade social modifique-na gradualmente e sem conflitos na direção da democracia. Fica bastante explícita sua descrença em mudanças radicais que não respeitem a subestrutura dos costumes do povo e sua crença num processo evolutivo natural de sentido altamente positivo, ou seja implicando num processo de aprimoramento cultural, processo que independe do ser humano, cabendo a este, somente a possibilidade de acelerá-lo. Fica assim bem definido o alcance e o limite da intenção do autor e dessa possibilidade de ação humana que para ele situa-se ao nível do Estado organizado politicamente. 
Esquematicamente:

análise da realidade social inexistência e impossibilidade imediata da prática democrática.

análise da realidade política

defazagem entre ideais da proposição politica e da prática política, impossibilidade da realização da democracia nos moldes atuais.

elaboração de técnicas políticas inadequação da técnica liberal $\mathrm{p}^{\prime}$ (ação do Estado) realidade social bras., busca e proposição de técnica autoritária de retormas graduais.

democracia consciência coletiva nacional - indivíduo dissolvido na Nação.

Podemos a partir dos dois esquemas perceber que se por um lado as alterações de seu vocabulário trouxeram maior precisão à análise das realidades, sem porém alterarem seu conteúdo significativo, no nível do objetivo e das técnicas para atingir esse objetivo, o enriçuecimento e a precisão dos termos cresce visivelmente. Se considerarmos o sentido pragmático que impõe ao seu trabalho podemos pensar numa cristalização das proposições de intervenção estatal na organização da sociedade, intervenção com técnicas autoritárias que aparecem agora de forma bastante definida e menos remetidas a uma justificação referidas aos princípios teóricos do liberalismo. A conjuntura internacional modificara-se na direção de uma intervenção estatal aceita, de um dirigismo necessário para coordenar as forças internas de um país. 